Hegel's Philosophy or the Spiritu in Search of Definition

\title{
La filosofía de Hegel o el espiritu en busca de definición
}

Antonio Gutiérrez Pozo

Universidad de Sevilla

agpozo@us.es

ORCID: 0000-0003-4143-1854

DOI: https://doi.org/10.15366/bp2021.27.020

Bajo Palabra. II Época. No 27. Pgs: 389-410

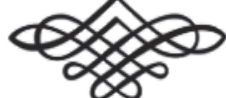


Recibido: 06/09/2020

Aprobado: 07/05/2021

\section{Resumen}

El espíritu según Hegel se duplica, o sea, se hace reflexionando sobre sí mismo, convirtiendo su ser en sí en ser para sí. Pero, por una parte, autoconocerse, hacerse objeto de sí mismo, implica extrañarse, hacerse otro. Por otra, el espíritu sólo puede reconocerse en el otro si el otro es también sí mismo. Sólo puede haber autorreconocimiento en el extrañamiento cuando éste no es radical. La meta del espíritu hegeliano es comprenderse y definirse. Esa definición total se logra en la filosofía. La historia de la filosofía es el progreso en la autocomprensión y realización del espíritu. Esta historia y el espíritu se consuman cuando se logra la comprensión filosófica del espíritu. Esto ocurre en la filosofía de Hegel.

Palabras clave: Hegel, espiritu, filosofia, extrañamiento, autorreconocimiento, definición.

\section{Abstract}

According to Hegel the spirit is duplicated, that is, it is made by reflecting on itself, turning its being-in-itself into being-for-itself. But, on the one hand, to know oneself, to become an object of itself, implies to alienate itself, to become another. On the other hand, the spirit can recognize oneself in the other only if the other is also oneself. There can be self-recognition only in estrangement when this estrangement is not radical. The goal of the Hegelian spirit is to understand and define itself. This total definition is achieved in philosophy. The history of philosophy is the progress in self-understanding and realization of the spirit. This history and the spirit are consummated when the philosophical understanding of spirit is achieved. This occurs in Hegel's philosophy.

Keywords: Hegel, spirit, philosophy, estrangement, self-recognition, definition. 


\section{Introducción}

El eSPíRITU Hegeliano, verdad esencial de lo real, consiste en lo que se hace, pero sólo existe pensándose, haciéndose objeto de él mismo. La meta del espíritu entonces no puede ser otra que autorreconocerse, para lo cual debe extrañarse y volver a sí en el mismo extrańamiento. Por esto podemos afirmar que el espíritu para Hegel es aquel ente que busca comprenderse, saber lo que es, el ente que busca su propia definición: "Para el espíritu lo más elevado (das Höchste) es saberse (wissen)" ${ }^{1}$. El espíritu y su historia de búsqueda y autorrealización se acaban -se consuman- cuando logra comprenderse y definirse. Esa definición sólo la conseguirá en la última filosofía, la hegeliana, aquella que resulta de todas las anteriores, lo cual, a su vez, convierte a la historia de la filosofía en la manifestación y autorrealización de su verdadero protagonista, el espíritu.

\section{El espíritu como devenir de sí mismo}

LA IDEA DE ESPÍRITU, piedra angular de la filosofía hegeliana, no puede ser entendida en términos teológicos, ni en clave religiosa como si fuera el 'alma' (pneuma) opuesta al cuerpo ${ }^{2}$. El espíritu hegeliano queda definido por el hecho de ser actividad y conciencia de modo inseparable. Esto quiere decir en principio que para Hegel el espíritu no es sustancia, no es sino que se hace y se hace en su conciencia de sí, mediante su saber de sí mismo. Lejos de todo ser sustancial y fijo, el espíritu hegeliano es "absoluta inquietud (absolute Unruhe)", y no es que sea y luego además actúe, es que "esta inquietud es el sí mismo (das Selbst)" ${ }^{3}$. No es cosa, nunca está quieto. Su ser se reduce a su acción: "La historia del espíritu es su propia obra (Tat), pues el espíritu es sólo lo que hace (tut)" ${ }^{4}$. El espíritu es hijo de su obrar. Contra el orden metafísico sustancialista del operari sequitur esse, el espíritu no es una cosa real que produzca sino que su realidad se produce. El dinamismo ontológico he-

\footnotetext{
${ }^{1}$ Hegel, G. W. F., Vorlesungen über die Philosophie der Weltgeschichte, Band I: Die Vernunft in der Geschichte (1830). Hamburg, Meiner, 1968, p. 65.

2 Jaeschke, W., Arndt, A., Die Klassische Deutsche Philosophie nach Kant, München, Beck, 2012, p. 632.

3 Hegel, G. W. F., Phänomenologie des Geistes (1807), Werke, Band 3, Frankfurt a. M., Suhrkamp, 1986, pp. 133, 26.

${ }^{4}$ Hegel, G. W. F., Grundlinien der Philosophie des Rechts (1821), Werke, Band 7, \$343, p. 504.
} 
geliano del esse sequitur operari responde a la sensibilidad moderna expresada en el Faust goetheano: Im Anfang war die Tat ${ }^{5}$. En consecuencia, el ser humano como ser espiritual por antonomasia tampoco está dado sin más, sino que se hace a sí mismo. Ya Marx aseguró que "Hegel entiende la autoproducción (Selbsterzeugung) del ser humano como un proceso (Prozeß)" y por eso concibe "el trabajo (Arbeit) como la esencia (Wesen) del ser humano", el cual por tanto consiste en "resultado (Resultat) de su propio trabajo" ${ }^{6}$. No tiene otra sustancia el ser humano que el trabajo en el que se autoproduce. Decir que el espíritu es procesual significa que no es una realidad ya dada, cósica e inmediata, algo en sí, lo que llama Hegel Realität, sino que se realiza y que sólo así logra realidad, Wirklichkeit en lenguaje hegeliano. Y es que, como señala Díaz, wirklich procede de wirken, actuar, de manera que el espíritu no es hasta que no actúa y sólo entonces es real, adquiere realidad, se realiza ${ }^{7}$. En efecto, Hegel ha escrito que "lo que es real (wirklich) puede actuar (wirken): su realidad (Wirklichkeit) se da a conocer mediante lo que produce (hervorbringt)" ${ }^{8}$. Ahora bien, el realizarse implica que el espíritu ya es posibilidad en sentido aristotélico y tiene que actualizarse. Este binomio del acto/potencia equivaldría al par Realität/ Wirklichkeit. Este presupuesto aristotélico es lo que subyace a la tesis hegeliana según la cual lo verdadero del espíritu "es el devenir de sí mismo (das Werden seiner selbst), el círculo (Kreis) que presupone y tiene por comienzo (Anfang) su término (Ende) como su fin (Zweck), y que sólo es real (wirklich) mediante la realización y su fin (Ende)" 9 . Pero cómo se hace el espíritu, en qué consiste esta tarea de autoproducción. Aquí interviene el segundo elemento que constituye la esencia del espíritu, la conciencia, el pensamiento.

\section{El espíritu como duplicación por reflexión}

Lo primero que Debemos asegurar es que para Hegel "el espíritu (Geist) es el pensar (Denken) en general" ${ }^{10}$. En otro lugar confirma que "el espíritu es el que piensa (der denkende)" ${ }^{11}$. Hegel establece un vínculo esencial entre el espíritu, que es pensar, y la conciencia, el gran concepto de la modernidad desde Descartes. Por

${ }^{5}$ Goethe, J. W., Faust. Eine Tragödie (1790-1832), München, Deutscher Taschenbuch, 1977, p. 40.

${ }^{6}$ Marx, K., Ökonomish-philosophische Manuskripte aus dem Jahre 1844, K. Marx-F. Engels Werke, Band 40, Berlin, Dietz, 1968, p. 574.

7 Díaz, C., Hegel, filosofo romántico, Madrid, Cincel, 1988, p. 50; El sueño hegeliano del estado ético, Salamanca, San Esteban, 1987, pp. 73ss.

${ }^{8}$ Hegel, G. W. F., Wissenschaft der Logik (1812-16), II, Werke, Band 6, p. 208.

${ }^{9}$ Hegel, G. W. F., Phänomenologie des Geistes, p. 23.

${ }^{10}$ Hegel, G. W. F., Grundlinien der Philosophie des Rechts, $\$ 4$, p. 46.

${ }^{11}$ Hegel, G. W. F., Vorlesungen über die Philosophie der Religion (1821-31), II, Werke, Band 17, p. 219. 
una parte, el espíritu según Hegel es ante todo conciencia: "La existencia inmediata (unmittelbare Dasein) del espíritu es la conciencia" ${ }^{12}$. Por otra, aunque verificada en el ser humano, no hay otra conciencia pensante que el espíritu: "La conciencia es el espíritu como saber (Wissen)", y más concretamente "la conciencia es el espíritu como saber concreto y reducido a la exterioridad (Äußerlichkeit)" ${ }^{13}$. En Hegel, escribe Heidegger, "la conciencia (Bewußtsein) es espíritu" 14. El espíritu es conciencia y, dado que según Kojève "la conciencia existe (existe) para ella misma" ${ }^{15}$, el espíritu será aquel ser que es para sí. Por esto podrá asegurar Marx que "el ser humano es un ser para sí mismo (für sich selbst)" ${ }^{16}$. Sólo existe haciéndose objeto de sí mismo. Sabemos que en la filosofía hegeliana todo es esencialmente espíritu, no sólo el arte, la historia, el estado o la religión, sino también las piedras, las reacciones químicas, el reino vegetal, etc., aunque en estos últimos ámbitos el espíritu todavía no sabe que es pensamiento y, por tanto, en rigor no lo es. Podemos decir que en estas regiones de lo real, que son espíritu, el espíritu no se ha manifestado, pues sólo lo hará en la conciencia, la cual consiste en el espíritu en su revelarse. Heidegger escribe que "la conciencia es el espíritu que se manifiesta (erscheinende Geist)" ${ }^{17}$. El espíritu es saber que se manifiesta y esto es precisamente la conciencia, saber que aparece. Por tanto, la meta de la existencia del espíritu es llegar a conocerse, a conocer su esencia y definir lo que realmente es. Saber lo que es, la autoconciencia, es el fin -como final y como objetivo- de la vida del espíritu.

El ser humano, como espíritu que es, es pensamiento. De hecho, escribe Hegel, "lo humano (das Menschliche) es humano debido (bewirkt) al pensamiento (Denken)", y por eso "el ser humano se diferencia del animal mediante el pensar" ${ }^{18}$. Ser pensamiento implica ser de una forma especial, distinta de los seres no pensantes. No supone nada nuevo en cuanto a su ser en sí, a su contenido, o sea, ser racional, libre, justo, social, etc. Lo propio de un ser pensante o reflexivo consiste en que sólo es lo que es en sí (como Realität) cuando lo es para sí (como Wirklichkeit). El espíritu -y por tanto el ser humano- no es nada hasta que 'eso', lo que sea, no lo es para sí, como objeto para él. Esta reflexividad distingue a lo humano. Por eso, afirma Hegel, "el embrión (Embryo) es en sí (an sich) un ser humano, pero no lo

\footnotetext{
${ }^{12}$ Hegel, G. W. F., Phänomenologie des Geistes, p. 38.

13 Hegel, G. W. F., Wissenschaft der Logik, I, Werke, Band 5, p. 17.

${ }^{14}$ Heidegger, M., Hegels Phänomenologie des Geistes (1930), Gesamtausgabe, Band 32, Frankfurt a. M., Klostermann, 1997, p. 36.

15 Kojève, A., Introduction à la lecture de Hegel (1933-39), Paris, Gallimard, 1968, p. 29.

${ }_{16}$ Marx, K., Ökonomish-philosophische Manuskripte aus dem Jahre 1844, p. 579.

17 Heidegger, M., "Erläuterung der 'Einleitung' zu Hegels Phänomenologie des Geistes" (1942), Hegel, Ga, Band 68, 1993, p. 132.

${ }^{18}$ Hegel, G. W. F., Enzyklopädie der philosophischen Wissenschaften (1817-31), I, Werke, Band 8, \$ 2, pp. 41s; Grundlinien der Philosophie des Rechts, $\$ 4$, p. 46.
} 
es para sí (für sich); el ser humano es para sí sólo como razón cultivada (gebildete Vernunft), que se ha hecho lo que es en sí" ${ }^{19}$. El ser humano realiza su en sí volviéndolo objeto de su razón. Hegel asegura que "cuando decimos que el ser humano es racional (vernünftig), que tiene la razón por naturaleza, sólo la tiene como disposición (Anlage), en germen (Keime)", de manera que "el niño sólo tiene la capacidad (Vermögen) o posibilidad real (reale Möglichkeit) de la razón, pero esto es como si no tuviera razón, como si no existiera (existiert) en él, pues ni puede hacer nada racional (Vernünftiges $z u$ tun), ni tiene conciencia racional" ${ }^{20}$. Hegel añade que "sólo en cuanto lo que el ser humano es en sí, deviene para él, y la razón es para sí, es realmente racional", y que esto es lo propio del espíritu y del ser humano como ser espiritual, que "lo que es en sí ha de convertirse en objeto (Gegenstand) para el ser humano, tiene que llegar a la conciencia" ${ }^{21}$. Lo que deviene para sí es lo mismo que lo que es en sí, pero sólo entonces lo es realmente, cuando ha devenido objeto de reflexión para él. Por eso Heidegger destaca que "Hegel no entiende el título 'reflexión' (Reflexion) psicológicamente como proceder, sino ontológicamente (ontologisch)" 22. Marcuse insiste en que "la reflexión (reflection) no es primariamente el proceso del pensar sino el proceso mismo del ser" ${ }^{23}$.

Para Hegel, el espíritu, la ciencia y la cultura en general, no pretenden otra cosa que convertir en 'para sî' lo que es 'en sí, o sea, extraer de sí lo interno. El ser humano es en sí justo y racional, pero sólo lo es en realidad (como Wirklichkeit), sólo lo realiza, cuando cobra conciencia de ello. En Hegel el realizarse del espíritu, el paso del en sí o Realität a Wirklichkeit, se da mediante la conciencia de sí o autoobjetivación. Por eso puede escribir que "el punto más importante para la naturaleza del espíritu no está en la relación de lo que él es en sí con lo que realmente (wirklich) es", o sea, con el hecho mismo del realizarse, sino, añade, "en cómo se conoce; porque el espíritu es esencialmente conciencia, este saberse (Sichwissen) es la determinación fundamental (Grundbestimmung) de su realidad (Wirklichkeit)" ${ }^{24}$. No hay ningún contenido nuevo, el ser humano no es algo más que justo y racional. La conciencia ni añade ni produce nada. Nada nuevo ha surgido que no estuviera ya en el ser en sí y natural del ser humano. La clave está en el modo consciente y para sí de serlo, que es lo que lo define como ser espiritual, que "el ser humano deviene para sí (für sich), se duplica (verdoppelt)", y que por tanto "lo que es como objeto

\footnotetext{
${ }_{19}$ Hegel, G. W. F., Phänomenologie des Geistes, p. 25.

${ }^{20}$ Hegel, G. W. F., Vorlesungen über die Geschichte der Philosophie (1805-31), I, Werke, Band 18, pp. 39s.

21 Ibid., p. 40

${ }_{22}$ Heidegger, M., “Erläuterung der 'Einleitung' zu Hegels Phänomenologie des Geistes”, p. 76.

${ }_{23}$ Marcuse, H., Reason and Revolution. Hegel and the Rise of Social Theory (1941), London, Routledge \& Kegan Paul, 1955, p. 143.

${ }^{24}$ Hegel, G. W. F., Wissenschaft der Logik, I, p. 27.
} 
(Gegenstand) es lo mismo que lo que es en si'”25. Un ser pensante es aquel ser que consiste en duplicarse. El ser espiritual es un ser natural y su contenido espiritual es el mismo que ya era como ser natural sólo que lo es en tanto se da en la reflexión, como objeto para él. Villacańas confirma que "ser espíritu es ser naturaleza reflejada", naturaleza consciente de $s^{26}$. Lo que distingue al espíritu y al ser humano es la manera de duplicarse. También la planta se duplica al producir un fruto. En el espíritu, la duplicación se produce en la autoconciencia, el acto reflexivo de vuelta a sí. Es una duplicación por reflexión. La diferencia reside en que si en la naturaleza según Hegel "la duplicación (Verdoppelung) se divide (zerfallen) en dos individuos (Individuen) diferentes", el germen y su resultado, la planta y su fruto, el padre y el hijo, en el espíritu es una duplicación en un solo ser, pues aquí lo que es en sí deviene para sí, mientras que "el fruto no es para el germen" ${ }^{27}$. El fruto sólo es para nosotros mismos, para el propio espíritu. Decir en Hegel que la razón es una cualidad natural del ser humano significa que es una posibilidad que está en germen, como lo es el fruto respecto de la planta, sólo que en el caso del ser humano la racionalidad cobra realidad (como Wirklichkeit) y él mismo deviene un ser racional cuando la razón se convierte en un objeto de reflexión para él mismo. Los seres naturales actúan mecánicamente mediante leyes. Los seres espirituales reflexivamente, a través de representaciones, siendo objetos para sí mismos. Decir que somos libres o racionales por naturaleza o en sí no quiere decir que somos libres o racionales porque una ley natural lo imponga, sino que lo somos cuando la libertad o la racionalidad son objetos para nosotros, cuando tenemos conciencia de ellas y nos las representamos. Dada esta esencialidad de la reflexión, el espíritu, según Hegel, sólo es, sólo se realiza, cuando se sabe a sí mismo y es objeto para sí, esto es, cuando se comprende y se define: "El espíritu es espíritu que se sabe a sí mismo (sich selbst wissender Geist); se sabe que es lo que para él es objeto" ${ }^{28}$.

\section{Autorreconocimiento en el extrañamiento}

El espíritu hegeliano no es sino que se hace. Ahora sabemos que se hace sabiéndose, convirtiéndose en objeto de sí: "Su acción (Tat), como espíritu, es hacerse (machen) objeto de su propia conciencia, concebirse explicitándose a sí mismo

\footnotetext{
25 Hegel, G. W. F., Vorlesungen über die Geschichte der Philosophie, I, p. 40.

${ }_{26}$ Villacańas, J. L., La filosofía del idealismo alemán II. La hegemonía del pensamiento de Hegel, Madrid, Síntesis, 2001. p. 265.

${ }^{27}$ Hegel, G. W. F., Vorlesungen über die Geschichte der Philosophie, I, p. 41; cfr. Villacañas, J. L., op. cit., p. 263.

${ }_{28}$ Hegel, G. W. F., Phänomenologie des Geistes, p. 572.
} 
(auslegend zu erfassen)" ${ }^{29}$. La propia autoconciencia es el ser del espíritu. El espíritu es inquietud, es su actividad y este actuar tiene la estructura de la autoconciencia. Se hace mediante su propia reflexión, mediante la conciencia de sí mismo como objeto, de manera que el propio espíritu se convierte en objeto y logra conciencia de sí como ese objeto. Se reconoce en lo que hace, en el objeto en que él mismo deviene. Ahora bien, para convertirse en su propio objeto, para objetivarse, ha de salir de sí y extrañarse, hacerse otro. En primer lugar hay que advertir que decir que el espíritu sale de sí y se exterioriza equivale a decir que se manifiesta, de modo que el manifestarse pertenece esencialmente a la espiritualidad. Hegel comprende "la manifestación (Manifestation) como un proceso (Prozeß) del espíritu" ${ }^{30}$. Es más, añade, "la determinabilidad (Bestimmtheit) del espíritu es pues la manifestación" ${ }^{1}$. Duplicarse es manifestarse, aparecer: "Aparecer (Erscheinen) y escindirse (Sich-Entzweien) son uno" 32 . Heidegger advierte que para Hegel "esta voluntad de mostrarse (Sichzeigen) es la esencia del espíritu. El aparecer (Erscheinen) es la voluntad esencial (Wesenswille) del espíritu" ${ }^{33}$. En segundo lugar, Hegel enseña que, al duplicarse, el espíritu deviene otro: "El espíritu se convierte en objeto, pues él es este movimiento, devenir otro (Anderes), o sea, objeto de sí mismo y superar (aufzuheben) este ser otro (Anderssein)" ${ }^{34}$. El espíritu es un en sí que es para sí, es decir, que vuelve a sí. Pero para volver a sí lo primero que tiene que hacer es convertirse en otro, perderse, extrañarse. Villacañas ha sugerido que no hay vida humana sin referencia a la alteridad ${ }^{35}$. Luego, lo que ha de hacer el espíritu en ese extrańarse es reconocerse, superar la alteridad y retornar a sí. Según Wood, "el espíritu para Hegel es un cierto tipo de actividad consciente, una que se hace o actualiza a sí misma haciendo algo fuera de sí mismo, y luego comprendiéndolo a la luz de una interpretación de lo que ha hecho" 36 .

Decíamos que el ser del espíritu es movimiento y ahora precisamos, con $\mathrm{Hy}$ ppolite, que es "la inquietud del sí mismo (inquiétude du Soi) que se ha perdido (perdu) y se reencuentra en su alteridad (altérité)", o sea, "el movimiento mediante el que se pone (pose) como otro distinto de sí para devenir sí mismo (devenir soi)" ${ }^{37}$.

${ }^{29}$ Hegel, G. W. F., Grundlinien der Philosophie des Rechts, $\$ 343$, p. 504.

${ }^{30}$ Hegel, G. W. F., Vorlesungen über die Philosophie der Religion, II, p. 245.

${ }^{31}$ Hegel, G. W. F., Enzyklopädie der philosophischen Wissenschaften, III, Band 10, \$383, p. 27.

${ }^{32}$ Hegel, G. W. F., Differenz des Fichteschen und Schellingschen Systems der Philosophie (1801), Werke, Band 2, p. 106.

${ }^{33}$ Heidegger, M., "Erläuterung der 'Einleitung' zu Hegels Phänomenologie des Geistes", p. 72.

${ }^{34}$ Hegel, G. W. F., Phänomenologie des Geistes, p. 38.

35 Villacañas, J. L., op. cit., p. 49.

${ }^{36}$ Wood, A. W., "Hegel and marxism", The Cambridge Companion to Hegel, F. C. Beiser (ed.), Cambridge, Cambridge University Press, 1993, 414-444, p. 427.

${ }^{37}$ Hyppolite, J., Genèse et structure de la 'Phénoménologie de l'esprit' de Hegel (1946), I, Paris, Aubier-Éd. Montaigne, 1956, p. 147. 
Es evidente que esta inquietud que define al espíritu hegeliano es imposible sin negatividad. Ser inquieto como modo de ser no sustancial supone negar toda quietud cósica en la que espíritu pudiera fijarse. Además, hacerse otro, extrañarse, es negarse a sí mismo, pero dado que ese alterarse es la condición para llegar a ser él, resulta que esa acción negativa no es meramente negadora sino más bien creadora. Para reconocerse, el espíritu tiene que negarse. Aunque puede parecer un defecto, una insuficiencia (Mangel), la negación es el alma del espíritu, lo que lo mueve, "lo negativo es el sí mismo" ${ }^{38}$. De ahí que Kojève sostenga paradójicamente que la acción mediante la que se hace el espíritu es negativa: "El espíritu no se realiza sino mediante la acción negadora (action négatrice), por tanto creadora (créatrice) en el mundo" 39 . Pero decir que la trasformación o inquietud forma parte del ser del espíritu no nos autoriza a sostener que para Hegel la negación es la nueva sustancia de lo real, que, como escribe Nancy, "la negatividad es donde se experimenta (s'éprouve) como nunca la mordiente de sentido (mordant du sens)" ${ }^{40}$. Admitimos, con Hegel, que no hay sentido sustancial, pero no, como asegura Nancy, que para Hegel no haya otro sentido que la propia negación. Verdaderamente Hegel critica la filosofía de la reflexión de Kant que se queda en la antítesis, en la negatividad ${ }^{41}$. Por supuesto en Hegel hay oposición, negación, pues "la vida (Leben) no puede ser considerada sólo como unión (Vereinigung) o relación (Beziehung), sino al tiempo como oposición (Entgegensetzung)", pero tampoco es sólo antítesis: "La vida es la unión (Verbindung) de la unión y la no unión (Nichtverbindung)" 42 .

Aunque se hace y su sí mismo es movimiento y no algo dado, el espíritu hegeliano no es el resultado de algo que no existiese de ninguna manera, sino el logro o la apropiación de algo que era (Realität) sin ser, sin verdadera realidad (Wirklichkeit). Lo que Hegel añade a esta recuperación del acto/potencia aristotélico es que dicha realización del sí mismo espiritual se verifica negándose en lo otro y autorreconociéndose en esa alteridad. Según Infante, "la mismidad no es ya propiedad sino apropiación, recuperación de sí misma a través de su negación, a través de lo otro" ${ }^{43}$. Para duplicarse, reconocerse y llegar a ser él mismo, el espíritu tiene que extrañarse. Duplicarse en Hegel es convertirse en otro sin dejar de ser él.

\footnotetext{
${ }^{38}$ Hegel, G. W. F., Phänomenologie des Geistes, p. 39.

39 Kojève, A., op. cit., p. 85.

${ }^{40}$ Nancy, J. L., L'inquiétude du négatif, Paris, Hachette, 1997, p. 10. Esta interpretación se funda sobre la comprensión derridiana del sujeto hegeliano como "aquello que puede contener (retenir) en sí su propia contradicción” (Derrida, J., "Il faut bien manger ou le calcul du sujet” (Entretien avec J. L. Nancy, 1989), Points de suspension. Entretiens, Paris, Galilée, 1992, 269-301, p. 276).

41 Hyppolite, J., op. cit., p. 145.

${ }^{42}$ Hegel, G. W. F., Systemfragment von 1800 (1800), Werke, Band 1, p. 422.

43 Infante del Rosal, F., "Hegel y la identidad como proceso", Eikasia: revista de filosofía, 58 (2014): 227-266, p. 241.
} 
El espíritu se pierde, se extraña, y en este perderse o extrańarse, vuelve a hallarse a sí. Tiene que ser otro para ser él mismo. Este es el fundamento de la metafísica hegeliana del espíritu, el salir de sí, duplicarse y extrańarse, y autorreconocerse. La vida del espíritu es el autorreconocerse. Sólo es autorreconociéndose, llega a ser lo que es sabiéndose a sí mismo. Tal es la peculiaridad de lo espiritual en Hegel. Una vez aclarado que Hegel entiende 'reconocer' como identificar dejando al margen otros dos significados del término (aceptar o admitir y agradecer), Ricoeur subraya que esta lucha del espíritu hegeliano por el reconocimiento representa "la principal revolución conceptual en el plano de los filosofemas (philosophèmes)" ${ }^{44}$. En esta lucha ya advertimos que no hay reconocimiento sin extrańamiento, pero el problema que plantea Ricoeur es cómo es posible que el espíritu deviniendo otro, extrañándose, pueda identificarse y reconocerse en esa alteridad. Resulta evidente que la única respuesta posible es que el otro es también sí mismo, de manera que la relación entre el espíritu y su otro es una relación de sí mismo a sí mismo: "El espíritu se hace otro (autre) a partir de su relación consigo mismo (à soi-même)" y entonces "la manera mediante la que el espíritu se encuentra en su otro permanece básicamente como una relación de sí a sí mismo (de soi à soi-mê$m e)^{\prime 45}$. No hay autoconciencia sin extrañamiento y reconocimiento de sí en la alteridad: "La autoconciencia sólo es algo, sólo tiene realidad, en tanto ella misma se extraña (entfremdet)" ${ }^{46}$. El extrañamiento sólo puede ser la condición de la autoconciencia si consiste en ponerse fuera a sí mismo como objeto: "El extrańamiento (Entäußerung) de la autoconciencia pone (setzt) la coseidad (Dingheit)", o sea, "se pone como objeto, pone al objeto como sí mismo" ${ }^{47}$. Es claro que "el espíritu está consigo mismo al vivir en el otro, sólo gracias a que aquello para lo que lo otro es, es lo mismo (dasselbe) que lo otro" ${ }^{48}$, es decir, puede reconocerse al objetivarse en algo otro porque el propio espíritu es su objeto ${ }^{49}$. Una vez que se objetiva y se extraña, se hace otro, lo propio del espíritu es que "vuelve a sí (in sich zurückgenommen) y está cabe sí (bei sich) en su ser otro" ${ }^{50}$.

Sólo puede haber autorreconocimiento en el extrañamiento cuando este último no es radical, cuando lo extraño es el propio sí mismo del espíritu, porque sólo entonces puede volver a sí mediante lo extraño. Ciertamente, confirma Hegel, "el espíritu comienza siendo duplicación, extrañamiento, pero sólo para poder encon-

\footnotetext{
${ }_{44}$ Ricoeur, P., Parcours de la reconnaissance. Trois études, Paris, Atock, 2004, p. 22.

45 Ibid., p. 265.

${ }^{46}$ Hegel, G. W. F., Phänomenologie des Geistes, p. 363.

47 Ibid., p. 575.

${ }^{48}$ Hegel, G. W. F., Vorlesungen über die Geschichte der Philosophie, I, p. 41.

49 Jaeschke, W., Arndt, A., op. cit., p. 633.

50 Hegel, G. W. F., Phänomenologie des Geistes, p. 575.
} 
trarse (finden) a sí mismo, para poder volver (kommen) a sí mismo" ${ }^{51}$. El espíritu es él mismo haciéndose otro, de modo que está contenido en el otro, está cabe sí en el otro. Duplicarse, extrañarse y volver a sí implica que lo propio del espíritu es "la conciencia de sí en su ser otro", de donde Hegel desprende que "la conciencia de otro (Anderen), de un objeto, necesariamente es en general autoconciencia, ser reflejado en sí (Reflektiertsein in sich)" 52 . Por esto, Heidegger señala que para Hegel "la esencia de la conciencia es la autoconciencia; todo cogito es un ego cogito me cogitare" 53 . La conciencia como percibir hacia fuera es un percibirse a sí misma. Kojève ha declarado que en Hegel "toda conciencia es a la vez necesariamente conciencia y autoconciencia" ${ }^{44}$. Si bien el conocimiento, como salir del sujeto al objeto o extrañamiento, produce una herida, la brecha abierta entre sujeto y objeto, el propio conocimiento según Hegel, en tanto supone el autorreconocimiento en lo otro, cierra la herida, de manera que "el conocer (Erkennen) abre (schlägt) la herida (Wunde) y la cura (heilt) (...) cura la herida que él mismo es" ${ }^{55}$. Al conocer, el intelecto divide, pero con la vuelta a sí mismo del sujeto en el objeto, con el autorreconocimiento, se unifica lo separado ${ }^{56}$.

\section{La radicalización del extrañamiento}

Se TRATA DE NO QUEDARSE confortablemente en la indubitabilidad de la inmanencia del cogito, en la interioridad de la autoconciencia, sino de salir al peligroso fuera del mundo -y de volver. Anticipando el nietzscheano gefährlich leben! del $\$ 283$ de Die fröhliche Wissenschaft, Hegel considera que lo que define al espíritu es su voluntad de salir de sí sin miedo al objeto, dejando atrás la comodidad del cogito para confrontarse con los peligros del mundo: "La vida del espíritu (Leben des Geistes) no es la vida que teme (scheut) a la muerte (Tode) y se mantiene pura de la devastación (Verwüstung), sino la que la soporta (erträgt) y en ella se mantiene (erhält). El espíritu gana (gewinnt) su verdad sólo en tanto se encuentra a sí mismo en el absoluto

\footnotetext{
${ }_{51}$ Hegel, G. W. F., Vorlesungen über die Geschichte der Philosophie, I, p. 42.

52 Hegel, G. W. F., Phänomenologie des Geistes, p. 135.

53 Heidegger, M., “Erläuterung der 'Einleitung' zu Hegels Phänomenologie des Geistes”, p. 76.

54 Kojève, A., op. cit., p. 310.

55 Hegel, G. W. F., Religions-Philosophie (1821), Gesammelte Werke, Band 17, Hamburg, Meiner, 1987, pp. 246, 249.

56 Ahora bien, puesto que unir es lo propio del amor, podemos deducir que tras el pensamiento hegeliano alienta una voluntad erótica, algo que Vitiello ha puesto de manifiesto: "La filosofía tiene en Hegel la función erótica de reunificar (riunificare) lo que estado separado (diviso)" (Vitiello, V., "Ethos ed eros in Hegel e Kant", Il Cannochiale. Rivista di Studi Filosofici, XIX (1983): 57-80, p. 59).
} 
desgarramiento (absoluten Zerrisenheit)" ${ }^{57}$. Sólo duplicándose y extrañándose, sólo experimentado los peligros de la exterioridad, puede llegar a ser él mismo. Cierto que también Descartes sale al mundo mediante la veracitas Dei, pero nada tiene que ver esta salida cartesiana con la hegeliana. Hegel afirma que el pensamiento cartesiano de la autoconciencia abre la modernidad: "Con Cartesius entramos en una filosofía propia e independiente (selbständige Philosophie), que sabe que procede esencialmente de la razón y que la conciencia de sí es un momento esencial de lo verdadero (Wahren)", de modo que "aquí ya podemos decir que estamos en casa (zu Hause)", que "con Descartes comienza la cultura (Bildung) y el pensar de los nuevos tiempos (neueren Zeit)" ${ }^{58}$. En la modernidad según Hegel se ha elevado a principio supremo el interior del espíritu autoconsciente frente al exterior del mundo ${ }^{59}$. Descartes inició esta afirmación de la autoconciencia. Pero Hegel no se queda ahí. Radicaliza el poder del pensar, liberándolo de las insuficiencias que todavía lo lastraban en Descartes y en Kant, y, así, realiza la verdad de las filosofías de estos pensadores que se quedó en potencia y que no desplegaron por miedo a la cosa en sí, al objeto. Esa verdad es el poder absoluto del pensar que Hegel despliega mediante la afirmación del espíritu que media toda realidad reconociéndose a sí mismo en ella. Al justificar la salida al mundo demostrando la validez objetiva de las ideas con la veracitas Dei, Descartes presupone el poder absoluto del objeto y anticipa la cosa en sí kantiana. El hecho de querer demostrar la validez objetiva de los propios pensamientos da por sentada la existencia de un mundo en sí no mediado por el cogito. Contra esta afirmación del carácter no mediable del objeto, irreducible al espíritu, Hegel sostiene su absoluta mediación por parte del pensamiento, lo que implica que el espíritu se reconoce totalmente a sí mismo en el objeto, que ya no es cosa en sí. Descartes ha presupuesto fatalmente el rígido esquema sujeto/objeto y, con ello, la separación del cogito respecto del mundo. En cambio para Hegel, según Hyppolite, "la conciencia humana de sí, incapaz de pensarse como un cogito separado, no se encuentra sino en el mundo que ella misma edifica (édifie)" ${ }^{60}$. La filosofía egológica moderna queda superada con el espíritu hegeliano, que ya no es el ego cartesiano replegado ante el mundo sino una conciencia que se ve a sí misma en la realidad, en una alteridad que ella misma se identifica ${ }^{61}$.

\footnotetext{
${ }^{57}$ Hegel, G. W. F., Phänomenologie des Geistes, p. 36.

${ }^{58}$ Hegel, G. W. F., Vorlesungen über die Geschichte der Philosophie, III, Werke, Band 20, p. 120.

59 "El principio (Prinzip) general es ahora aferrarse (festzuhalten) a la interioridad (Innerlichkeit) y considerar indebido (ungehörig) el retorno a la autoridad (Autorität) de la muerta exterioridad (tote Äußerlichkeit)", y "según este principio de la interioridad ahora es el pensar, el pensar para sí (Denken für sich), la más pura cima de lo más interior (Innersten)" (Ibid).

${ }^{60}$ Hyppolite, J., Études sur Marx et Hegel (1955), Paris, Éditions Marcel Rivière et Cie, 1965, p. 102.

${ }^{61}$ Esto es lo que permite a Heidegger declarar que "para Hegel lo absoluto (das Absolute) es el espíritu" y que "el espíritu es dios (Gott), la realidad (Wirklichkeit), el ente (Seiende)" (Heidegger, M., Hegels Phänomenologie des
} 
Hegel considera que lo que ha lastrado al idealismo de Descartes y Kant ha sido la angustia ante el objeto, pues "la filosofía crítica ya convirtió (machte) la metafísica en lógica, pero por miedo (Angst) al objeto (Objekt) dio a las determinaciones lógicas un significado (Bedeutung) esencialmente subjetivo" ${ }^{62}$. Esa angustia ante el objeto impidió que consideraran que el objeto es el propio espíritu que, por ello, puede reconocerse en él. Si Hegel sostiene al contrario que el espíritu se ve a sí mismo en el objeto exterior es porque es él mismo el que se exterioriza, se extraña. Justo esto es lo único que justifica que pueda reconocerse en esa alteridad. Por eso para Hegel "la fuerza $(K r a f t)$ del espíritu es tan grande como su exteriorización (Äußerung)", lo que implica que el espíritu "no tiene que aferrarse a la forma de la autoconciencia contra la forma de la sustancialidad (Substantialität) y la objetividad (Gegenständlichkeit), como si tuviera miedo de su extrańamiento (Entäußerung); la fuerza del espíritu reside más bien en permanecer igual a sí mismo en su extrañamiento" ${ }^{33}$. El espíritu hegeliano evita la clausura del interior de la autoconciencia y arrostra el peligro del mundo para reconocerse en él e identificárselo. Lejos de encerrarse en sí "como el retirarse (Zurückziehen) de la autoconciencia en su pura interioridad (Innerlichkeit)", y de perderse en la dura exterioridad "como el mero hundimiento (Versenkung) de la autoconciencia en la sustancia y el no ser (Nichtsein) de su diferencia", el espíritu según Hegel se muestra "como este movimiento del sí mismo, que se extraña (entäußert) de sí y se hunde en su sustancia, y como sujeto, partiendo de ella, se adentra en sí, convirtiendo a la sustancia en objeto y contenido (Inhalt), al superar esta diferencia (Unterschied) de la objetividad y el contenido" ${ }^{64}$. Además de convertir en objeto a la antigua sustancia de la metafísica, el espíritu logra que la objetividad ya no se distinga de su propio contenido espiritual.

El problema crucial se plantea cuando el espíritu se extraña sin poder volver a sí porque aquello donde debía reconocerse le resulta absolutamente extraño. Aquí halla Hegel la diferencia entre extrañamiento (Entäußerung) o movimiento del salir fuera y alienación (Entfremdung), que se produce cuando el espíritu se pierde definitivamente en el fuera, no se reconoce en la exterioridad y no se produce la vuelta a sí. La alienación es un extrañamiento sin retorno. Boey advierte que sin extrańamiento no puede haber alienación, pero que no todo extrańamiento termina necesariamente en alienación: "La alienación (aliénation) se injerta (se greffe) en la exteriorización (extériorisation), pero no se puede decir lo contrario.

Geistes, p. 183)

${ }^{62}$ Hegel, G. W. F., Wissenschaft der Logik, I, p. 45.

${ }^{63}$ Hegel, G. W. F., Phänomenologie des Geistes, pp. 18, 588.

64 Ibid., p. 587. 
Efectivamente, la alienación es una exteriorización que no se comprende (comprend) a sí misma" ${ }^{65}$. En este sentido, Cerezo afirma que "lo extraño no es sin más lo ajeno, aunque sí su condición de posibilidad", de modo que "no hay ajenidad sin extrańeza, pero puede haber extrańeza sin ajenidad" ${ }^{66}$. Hyppolite ya señaló que el extrańamiento, "la objetivación es el proceso por el que el ser humano se hace cosa (chose) y se expresa (exprime) o se exterioriza en la naturaleza por el trabajo y la obra (oeuvre)", mientras que "la alienación es el proceso por el que este ser ahí exteriorizado deviene extraño a él mismo, se encuentra (trouve) en su obra como otro de sí, o más bien no se encuentra él mismo, no puede reconocerse" ${ }^{67}$. La alienación es aquel modo de verificarse la exteriorización o extrañamiento en el que el sujeto no puede reapropiarse de sí porque la ajenidad es ya insalvable y no hay posibilidad de autorreconocimiento ${ }^{68}$. La alienación o ajenidad significa la radicalización del extrańamiento, su endurecimiento y cosificación, lo que hace imposible la mediación espiritual. Una extrańeza radical evita que el ser humano pueda reconocerse a sí mismo en su propia exteriorización. Se quiebra el circuito, de modo que la obra que él mismo crea, el objeto donde se extraña, en vez de permitirle el retorno del autorreconocimiento, se independiza, se cosifica y se vuelve contra él. En consecuencia, se pierde en lo que él mismo ha construido. Al impedir el reconocimiento de sí no se puede cerrar la herida que -recordemosabría el conocer ${ }^{69}$.

${ }_{65}$ Boey, C., L'aliénation dans la 'Phénomenologie de l'esprit' de Hegel, Paris-Bruges, Desclée de Brouwer, 1970, pp. 82 s.

${ }^{66}$ Cerezo P., "La distinción entre extrañamiento (Entäußerung) y alienación (Entfremdung) en la Fenomenología del espiritu”, Hegel y el reino del espiritu, Granada, Universidad de Granada, 2018, 67-103, pp. 81s.

${ }^{67}$ Hyppolite, J., Etudes sur Marx et Hegel, p. 86.

${ }^{68}$ Cerezo, P., op. cit., p. 93.

69 Hegel expone este problema concretamente en el lenguaje. En principio, según Hegel, el sujeto individual, único y concreto que es cada uno intenta expresar a los otros mediante el lenguaje su peculiar singularidad: "El lenguaje (Sprache) es el ser ahí (Dasein) del puro sí mismo como sí mismo; con él entra en la existencia (Existenz) la individualidad de la autoconciencia que es para sí, de modo que es para otros” (Hegel, G. W. F., Phänomenologie des Geistes, p. 376). Pero no puede hacerlo porque el lenguaje es algo social, de todos, luego el yo no se puede reconocerse a sí mismo plenamente en él: "Lo que sólo yo pienso (meine) es mío, me pertenece como este individuo particular (besonderen Individuum); pero si el lenguaje sólo expresa (ausdrückt) lo universal (Allgemeines), no puedo decir (sagen) lo que sólo yo pienso" (Hegel, G. W. F., Enzyklopädie der philosophischen Wissenschaften, I, Band $8, \$ 20$, p. 74). Al usar un medio objetivo, general, el yo individual se desindividualiza. El yo sólo puede usar el lenguaje para llegar al otro al precio de sacrificar su exclusiva individualidad. En efecto, "el manifestarse (Erscheinen) del yo es inmediatamente el extrańamiento (Entäußerung) y la desaparición (Verschwinden) de este yo" (Hegel, G. W. F., Phänomenologie des Geistes, p. 376). El lenguaje es siempre para el otro, de modo que el extrańamiento del yo en él es sin retorno. Por mucho que lo use como único vehículo comunicativo, el lenguaje siempre le parecerá al yo individual algo ajeno, pues nunca podrá reconocerse absolutamente en él. El lenguaje que uso para expresar mi mismidad nunca es mío sino de otros, no me pertenece, es un elemento alienador en el que me pierdo, donde no puedo reconocerme totalmente aunque logre expresarme parcialmente. Desde esta perspectiva, la poesía es la lucha por conseguir que ese elemento público, alienador, se convierta verdaderamente en expresión de lo único individual, de modo que el individuo pueda reconocerse plenamente en él. No otra cosa pretende el poeta. 


\section{La historia de la filosofía como progreso de la definición del espíritu}

El eSPíritu es Su HACERSE. Su ser es histórico. Se hace pensándose, haciéndose él mismo objeto de su propia reflexión. Preguntarse por sí mismo y llegar a saber qué es forman parte esencial del ser del espíritu. Este pensarse en el tiempo con valor ontológico, pues en él se constituye el espíritu, es la historia misma. Toda la historia no es sino la manifestación de la conciencia a sí misma. El final de la historia, su meta, se alcanza cuando el espíritu logra la conciencia de su naturaleza cuando llega a saber lo que es. El objetivo final del espíritu no puede ser otro que comprenderse a sí mismo, definirse. Sólo entonces se realiza absolutamente. El espíritu es aquel tipo de ser que sólo es cuando se sabe a sí mismo, cuando se define, de modo que se acaba, completa o consume cuando sabe lo que es. Cuando esto ocurre, la conciencia, el sujeto de ese comprender (el espíritu), y su objeto (el espíritu) coinciden. Esta coincidencia señala el final del proceso de autoconocimiento. El espíritu entonces ya se ha consumado. Ahora bien, esa definición que contiene la autoconciencia del espíritu sólo puede obtenerse en la filosofía. La experiencia artística y religiosa expresan lo absoluto en lo sensible, algo que hace imposible que el espíritu se conozca. Sólo el pensamiento puro lo permite ${ }^{70}$. Realmente, precisa Taylor, "el arte es un modo de conciencia (mode of consciousness) de la idea, pero no es una representación de ella"71, es decir, el espíritu se manifiesta en el arte pero no se representa, no se pone como objeto, que es lo que sí hace la filosofía. Por eso, según Hegel, el artífice de la historia de la filosofía, "el agente (Werkmeister) de este trabajo de milenios es el espíritu viviente (lebendige Geist) cuya naturaleza pensante (denkende Natur) es llevar a su conciencia (Bewußtsein) lo que él es" ${ }^{72}$. El espíritu se consume cuando consigue una comprensión filosófica de sí mismo. Tengamos presente que la expresión 'comprensión filosófica del espíritu' es un genitivo tanto objetivo como subjetivo: el espíritu es el objeto de esa comprensión, pero también el sujeto que la lleva a cabo.

Así se aclara el papel de la filosofía en el pensamiento hegeliano. Es significativo que Hegel contraponga la filosofía a la anatomía al inicio de su Phänomenologie des Geistes señalando que cuando uno sabe que "la noción de anatomía es el conocimiento de las partes del cuerpo considerado en su existencia inerte (unlebendigen Dasein), está convencido de no poseer todavía la cosa misma misma (Sache), el contenido (Inhalt) de esta ciencia", mientras que "la filosofía se hallaría en desigualdad (Ungleichheit)" ${ }^{73}$. En el caso de la anatomía, tener el concepto no supone tener la ciencia,

\footnotetext{
${ }_{70}$ Garaudy, R., La pensée de Hegel, Paris, Bordas, 1966, pp. 165-177.

71 Taylor, Ch., Hegel, Cambridge, Cambridge University Press, 1975, p. 470.

72 Hegel, G. W. F., Enzyklopädie der philosophischen Wissenschaften, I, Band 8, \$13, p. 58.

73 Hegel, G. W. F., Phänomenologie des Geistes, pp. $11 \mathrm{~s}$.
} 
su contenido, pues saber qué es la anatomía no implica poseer ningún conocimiento anatómico. Sin embargo, saber qué es la filosofía es saber filosofía. La anatomía ni ha empezado con su definición; la filosofía se acabaría cuando sepa lo que es. Como el espíritu, la filosofía no sólo busca su definición sino que consiste en esa búsqueda. Filosofía y espíritu se acaban y consumen cuando saben qué son. Pero el hecho de que esta afirmación esté justo al inicio del libro dedicado a la fenomenología del espíritu, es decir, a las experiencias por las que pasa el espíritu hasta llegar al saber absoluto, al saber pleno de sí mismo, cuando él es sujeto y objeto de su propio conocimiento, sólo puede significar que esa tesis sobre la filosofía involucra al propio espíritu en relación con la filosofía. El mismo libro que afirma esa peculiaridad de la filosofía es el libro que narra las aventuras del espíritu desde la pura sensación hasta el saber absoluto de sí. Esto quiere decir no sólo que la filosofía y el espíritu se consuman cuando se comprenden y se definen, sino que están vinculados esencialmente en esta operación. Existe un nexo esencial entre la filosofía y el espíritu. En la filosofía se despliega el espíritu, que toma conciencia de sí en ella. No existe en las estrellas, en el más allá metafísico del topos hyperouranos; el espíritu hegeliano es en la filosofía, en la ciencia: "El espíritu es aquello mediante lo cual se constituye (konstituiert) la ciencia, la cual no es sino su exposición (Darstellung)" ${ }^{\prime 4}$. El espíritu es saberse y donde se sabe finalmente es en la filosofía, que es por ello el lugar del saber absoluto, el lugar donde el espíritu es sujeto y objeto de sí mismo, donde él como sujeto se conoce a sí mismo como objeto. Como lugar del saber absoluto, es el lugar de la verdad, donde se sabe a sí misma la esencia de lo real, el espíritu. Es patente entonces, como afirma Cordúa, que la meta de la historia de la filosofía es "establecer la verdad del todo o de lo absoluto"75.

Esto es lo que representa la filosofía para Hegel y lo que explica el sentido de uno de sus textos más conocidos y profundos: "Sobre el enseñar (belehren) cómo debe ser el mundo, la filosofía siempre llega demasiado tarde. Como pensamiento (Gedanke) del mundo, ella sólo aparece (erscheint) después de que la realidad (Wirklichkeit) ha perfeccionado (vollendet) y terminado su proceso de formación", de manera que "cuando la filosofía pinta su gris sobre gris (Grau in Grau) ya ha envejecido una figura de vida (Gestalt des Lebens) y no se deja rejuvenecer (verjüngen) con gris sobre gris sino sólo conocer (erkennen). Sólo cuando irrumpe (einbrechenden) el ocaso (Dämmerung) inicia su vuelo (Flug) el búho (Eule) de Minerva" ${ }^{76}$. Sólo cuando la realidad llega ya a su fin aparece la idealidad filosófica para reconstruirla en el ámbito intelectual. Cuando lo real se ha consumado, interviene lo que parece un ańadido, algo secundario, pero que en Hegel lo es todo, la comprensión y la definición. Cuando ya todo ha sido, sólo

\footnotetext{
${ }_{74}$ Hegel, G. W. F., Wissenschaft der Logik, I, p. 17.

${ }^{75}$ Cordúa, C., "Hegel”, La filosofía del s. XIX, J. L. Villacańas (ed.), Madrid, Trotta, 2013, 53-83, p. 56.

${ }^{76}$ Hegel, G. W. F., "Vorwort" (1820), Grundlinien der Philosophie des Rechts, pp. 27s.
} 
falta comprender. El gris sobre gris de la teoría no puede sustituir el vigoroso verdor de la vida real. Sólo puede comprenderlo. El ente se ha desplegado materialmente, pero le falta lo esencial, el momento de la comprensión que se verifica en la definición. Comprenderse y definirse, ese es el verdadero fin y meta de toda la experiencia de manifestaciones por las que pasa el espíritu. Esto ocurre por fin en la filosofía, y especialmente en la filosofía de Hegel. Con ello, el espíritu acaba. La filosofía es el movimiento lógico y necesario del espíritu por autoconocerse. De ahí que fuese tan importante para la filosofía saber lo que es ella misma, porque la propia filosofía es el autoconocimiento del espíritu ${ }^{77}$.

Igual que el espíritu es histórico, también lo es la filosofía, como ámbito de su despliegue autoconsciente. La diversidad histórica de las filosofías no puede ocultarnos el hecho de que se trata de una única filosofía que se modula históricamente según las distintas inflexiones en que se va revelando el espíritu. De aquí extrae Hegel tres consecuencias. La primera es que "en todo tiempo sólo ha habido una filosofía (eine Philosophie gewesen)" 78. Para Hegel "la historia (Geschichte) de la filosofía muestra en las diferentes filosofías que aparecen sólo una filosofía repartida (aufteils) en diferentes escalones de formación (Ausbildungsstufen)" ". La segunda es que "la serie (Folge) de los sistema filosóficos no es arbitraria (zufällige) sino la necesaria sucesión de la evolución (Stufenfolge der Entwicklung) de esta ciencia" ${ }^{80}$. La historia de la filosofía es el progreso en la definición del espíritu, el progreso de su autoconciencia. Hasta llegar, añade Hegel, a "la última filosofía (letzte Philosophie) que es el resultado (Resultat) de todas las filosofías anteriores (vorhergehenden) y por ello debe contener los principios de todas ellas, razón por la que, aunque es otra filosofía (anders Philosophie), es la más desarrollada (entfaltetste), la más rica (reichste) y la más concreta (konkreteste)" ${ }^{81}$. Esta tesis valdría como tercera consecuencia: si todas las filosofías son una que se va desarrollando según la lógica del autoconocimiento final del espíritu, ha de haber "una última filosofía que contiene (enthält) por ello a todas las anteriores, que compendia $(f a \beta t)$ en sí todas las etapas (Stufen)" ${ }^{82}$. En ella, la filosofía logra la conciencia de lo que

\footnotetext{
77 Dado que en la filosofía se expresa la lógica del espíritu en su proceso de autoconciencia, Hegel asegura que "la filosofía es la ciencia objetiva (objektive) de la verdad, la ciencia en su necesidad, ningún opinar (Meinen)" (Hegel, G. W. F., "Einleitung" (Heidelberger Niederschrift) (1817), Vorlesungen über die Geschichte der Philosophie, I, p. 30). Habida cuenta de que "una opinión (Meinung) es una representación subjetiva (subjektive Vorstellung)", Hegel deduce que "la filosofía no contiene opiniones. No hay opiniones filosóficas" (Ibid.). En la filosofía entonces no caben las ocurrencias, no es cuestión de opiniones personales, pues en ella sólo es (se manifiesta) la verdad no arbitraria sino necesaria del espíritu, la verdad lógico/metafísica de lo real.

${ }^{78}$ Hegel, G. W. F., Vorlesungen über die Geschichte der Philosophie, III, Werke, Band 20, p. 461.

${ }^{79}$ Hegel, G. W. F., Enzyklopädie der philosophischen Wissenschaften, I, Band 8, \$13, p. 58.

${ }^{80}$ Hegel, G. W. F., Vorlesungen über die Geschichte der Philosophie, III, p. 461.

${ }^{81}$ Hegel, G. W. F., Enzyklopädie der philosophischen Wissenschaften, I, Band 8, \$ 13, p. 58; Vorlesungen über die Geschichte der Philosophie, III, p. 455.

${ }^{82}$ Hegel, G. W. F., Vorlesungen über die Geschichte der Philosophie, III, p. 461.
} 
es ella misma, autoconciencia del espíritu, y al hacerlo se convierte en la filosofía donde el espíritu logra la conciencia plena de sí mismo. La filosofía sólo puede terminar cuando el espíritu se realiza y, a su vez, el espíritu sólo se consuma en la filosofía que logra conciencia absoluta de él, puesto que en esa conciencia el propio espíritu ejerce de sujeto. El espíritu llega a su autoconciencia final en la última filosofía. Al afirmar que "la filosofía de hoy, la última, contiene todo lo que ha producido el trabajo de milenios, y que es el resultado de todo lo que la ha precedido" ${ }^{83}$, Hegel sugiere con claridad que esa filosofía última y actual es por supuesto la suya, que deviene entonces en lugar del saber absoluto. La comprensión y definición filosófica del espíritu que lo acaba y consuma sólo ocurre plenamente con el pensamiento de Hegel. En la filosofía hegeliana, "la lucha (Kampf) de la autoconciencia finita (endlichen Selbstbewußtseins) con la autoconciencia absoluta de sí mismo (absoluten Selbstbewußtseins) ha acabado", pues "la conciencia finita ha dejado de ser finita" ${ }^{84}$. En efecto, en la autoconciencia finita del pensamiento hegeliano, el espíritu absoluto e infinito ha llegado a la autorrealización mediante la conciencia de sí. Por tanto, añade, "toda la historia universal y en particular la historia de la filosofía representa (darstellt) esta lucha, que ahora parece llegar a su meta (Ziel)" ${ }^{85}$. La definición que contiene la comprensión filosófica del espíritu y su realización final, según Hegel, sólo podía ser esta: "El absoluto ( $A b$ solute) es el espíritu", y "encontrar esta definición y entender (zu begreifen) su sentido (Sinn) y contenido era la tendencia (Tendenz) absoluta de toda la cultura (Bildung) y la filosofía" ${ }^{86}$. El absoluto, o sea, el espíritu, es la conciencia y su objeto -el mundo-, el saber y lo sabido, el pensar y el ser. Es necesario precisar que para Hegel con la consumación del espíritu no se llega sin más al fin de la historia. Lo que se ha acabado es una etapa de la historia humana y del espíritu, aquélla en la que éste se buscaba a sí mismo y perseguía su definición comprensiva. Pero con ello, advierte Hegel, "una nueva época (neue Epoche) ha nacido (entsprungen) en el mundo" ${ }^{87}$, una época en la que el espíritu ya es libre porque ya no tiene que autoconocerse pues ya lo ha hecho.

\section{Conclusión: contra la definición definitiva}

Sostenemos QUe la tesis de la consumación del espíritu se contradice con la finitud humana que Hegel supera convirtiéndola en infinitud al considerarla ma-

\footnotetext{
${ }^{83}$ Hegel, G. W. F., Einleitung in die Geschichte der Philosophie (1823-28), Hamburg, Meiner, 1966, p. 53.

${ }^{84}$ Hegel, G. W. F., Vorlesungen über die Geschichte der Philosophie, III, p. 460.

85 Ibid.

${ }^{86}$ Hegel, G. W. F., Enzyklopädie der philosophischen Wissenschaften, III, Band 10, \$384, p. 29.

${ }^{87}$ Hegel, G. W. F., Vorlesungen über die Geschichte der Philosophie, III, p. 460.
} 
nifestación de la verdad absoluta, el espíritu ${ }^{88}$. Una definición supone acabamiento sólo si es posible una proposición absoluta, que no presuponga ninguna y se diga totalmente. Esto es el saber absoluto, una conciencia que se identifica con su objeto, porque cuando el objeto excede a su conciencia tenemos que seguir hablando, que es lo que impide la definición definitiva. Pero no existe tal proposición definitoria concluyente. No podemos dejar de reconocer que la finitud humana nos enseña que cada palabra, cada texto, llama a otro y éste a su vez a otro, y así indefinidamente. Esto quiere decir que, en el fondo, ninguna definición se comprende totalmente a sí misma porque apela siempre a algo que queda por decir. Una definición es un texto y ningún texto es autotrasparente, pues siempre supone un residuo de objetividad por decir que es lo que le da sentido. El mito de la identidad conciencia/ objeto se quiebra si reparamos en la finitud humana, que apela más bien al diálogo sin fin. Debemos tomarnos en serio el título del trabajo: el espíritu en busca de definición, siempre en busca. Contra Hegel, la búsqueda es interminable porque el espíritu, que es protagonista, actúa tanto de sujeto como de objeto inagotable. De esta definición hay que decir lo mismo que decía Aristóteles de la filosofía, que era zetoumene episteme ${ }^{89}$, ciencia que constantemente se busca. Esa búsqueda es un diálogo sin fin del espíritu como sujeto buscando definirse a sí mismo como objeto. No hay otro espíritu que el que existe en el mundo humano, y para el ser humano lo único absoluto es la búsqueda.

\footnotetext{
${ }^{88}$ Garaudy apuntó que el concepto hegeliano de espíritu, que es proceso, acción, se contradice con la tesis de su acabamiento, pues si termina su historia se convierte en cosa, en lo contrario de la acción ejecutiva en que consiste (Garaudy, R., op. cit., p. 200).

89 Aristóteles, Metafísica, ed. de V. García Yebra, Madrid, Gredos, 1998, 983a21, 995a24, 996b3, pp. 18, $98,106$.
} 


\section{REFERENCIAS BIBLIOGRÁFICAS}

Aristóteles, Metafísica, ed. de V. García Yebra, Madrid, Gredos, 1998.

Boey, C., L'aliénation dans la 'Phénomenologie de l'esprit' de Hegel, Paris-Bruges, Desclée de Brouwer, 1970.

Cerezo P., "La distinción entre extrańamiento (Entäußerung) y alienación (Entfremdung) en la Fenomenología del espiritu", Hegel y el reino del espiritu, Granada, Universidad de Granada, 2018, pp. 67-103.

Cordúa, C., "Hegel”, La filosofía del s. XIX, J. L. Villacañas (ed.), Madrid, Trotta, 2013, pp. 53-83.

Derrida, J., "Il faut bien manger ou le calcul du sujet" (Entretien avec J. L. Nancy, 1989), Points de suspension. Entretiens, Paris, Galilée, 1992, pp. 269-301.

Díaz, C., Hegel, filósofo romántico, Madrid, Cincel, 1988.

, El sueño hegeliano del estado ético, Salamanca, San Esteban, 1987.

Garaudy, R., La pensée de Hegel, Paris, Bordas, 1966.

Goethe, J. W., Faust. Eine Tragödie (1790-1832), München, Deutscher Taschenbuch, 1977.

Hegel, G. W. F., Systemfragment von 1800 (1800), Werke, Band 1, Frankfurt a. M., Suhrkamp, 1986.

, Differenz des Fichteschen und Schellingschen Systems der Philosophie (1801), Werke, Band 2. Band 18-20.

, Vorlesungen über die Geschichte der Philosophie (1805-31), I-III, Werke, , Phänomenologie des Geistes (1807), Werke, Band 3.

, Wissenschaft der Logik (1812-16), I-II, Werke, Band 5-6.

Band 8-10.

, Enzyklopädie der philosophischen Wissenschaften (1817-31), I-III, Werke, , Grundlinien der Philosophie des Rechts (1821), Werke, Band 7.

, Religions-Philosophie (1821), Gesammelte Werke, Band 17, Hamburg, Meiner, 1987. Band 16-17.

, Vorlesungen über die Philosophie der Religion (1821-31), I-II, Werke, , Einleitung in die Geschichte der Philosophie (1823-28), Hamburg, Meiner, 1966. 
, Vorlesungen über die Philosophie der Weltgeschichte, Band I: Die Vernunft in der Geschichte (1830), Hamburg, Meiner, 1968.

Heidegger, M., Hegels Phänomenologie des Geistes (1930), Gesamtausgabe, Band 32, Frankfurt a. M., Klostermann, 1997.

, "Erläuterung der 'Einleitung' zu Hegels Phänomenologie des Geistes" (1942), Hegel, Ga, Band 68, 1993.

Hyppolite, J., Genèse et structure de la 'Phénoménologie de l'esprit' de Hegel (1946), I, Paris, Aubier-Éd. Montaigne, 1956.

1965. , Études sur Marx et Hegel (1955), Paris, Éditions Marcel Rivière et Cie,

Infante del Rosal, F., "Hegel y la identidad como proceso", Eikasia: revista de filosofía, 58 (2014): 227-266.

Jaeschke, W., Arndt, A., Die Klassische Deutsche Philosophie nach Kant, München, Beck, 2012.

Kojève, A., Introduction à la lecture de Hegel (1933-39), Paris, Gallimard, 1968.

Marx, K., Ökonomish-philosophische Manuskripte aus dem Jahre 1844, K. Marx-F. Engels Werke, Band 40, Berlin, Dietz, 1968.

Marcuse, H., Reason and Revolution. Hegel and the Rise of Social Theory (1941), London, Routledge \& Kegan Paul, 1955.

Nancy, J. L., Linquiétude du négatif, Paris, Hachette, 1997.

Ricoeur, P., Parcours de la reconnaissance. Trois études, Paris, Atock, 2004.

Taylor, Ch., Hegel, Cambridge, Cambridge University Press, 1975.

Villacañas, J. L., La filosofía del idealismo alemán II. La hegemonía del pensamiento de Hegel, Madrid, Síntesis, 2001.

Vitiello, V., "Ethos ed eros in Hegel e Kant", Il Cannochiale. Rivista di Studi Filosofici, XIX (1983): 57-80.

Wood, A. W., "Hegel and marxism", The Cambridge Companion to Hegel, F. C. Beiser (ed.), Cambridge, Cambridge University Press, 1993, pp. 414-444. 
